Revue

Revue de l'histoire des religions

del'histoire

des religions

$3 \mid 2008$

Varia

\title{
Jean-Philippe Schreiber (éd.), Théologies de la guerre
}

\author{
Julie Saada
}

\section{OpenEdition}

Journals

Édition électronique

URL : http://journals.openedition.org/rhr/6803

DOI : 10.4000/rhr.6803

ISSN : 2105-2573

Éditeur

Armand Colin

Édition imprimée

Date de publication : 1 septembre 2008

Pagination : 434-437

ISBN : 978-2200-92445-4

ISSN : 0035-1423

\section{Référence électronique}

Julie Saada, « Jean-Philippe Schreiber (éd.), Théologies de la guerre », Revue de I'histoire des religions [En ligne], 3 | 2008, mis en ligne le 14 janvier 2010, consulté le 22 septembre 2020. URL : http:// journals.openedition.org/rhr/6803 ; DOI : https://doi.org/10.4000/rhr.6803

Tous droits réservés 
la contraception ne saurait être celle de tous ceux qui s'y trouvent engagés » et que la sexualité n'est pas tant un domaine à légiférer qu'un " espace à évangéliser, le lieu d'une possible croissance, où rien n'est donné à l'avance » (p. 121). L'ouverture des auteurs à la réflexion met ainsi parfois leur discours raisonné et prudent, soucieux du respect à garder envers les personnes concernées, en porte à faux avec les formules abruptes du magistère.

Camille de Villeneuve, École Pratique des Hautes Études, Paris.

Jean-Philippe SchreIBER (éd.), Théologies de la guerre, Bruxelles, Éditions de l'Université de Bruxelles, 2006, $24 \mathrm{~cm}, 146$ p. («Spiritualités et pensées libres»), 17 €.

Ce collectif rassemble les interventions faites au séminaire international d'anthropologie religieuse à l'Université de Bruxelles (centre interdisciplinaire d'étude des religions et de la laïcité), initié par Jacques Marx, ancien vice-président de l'Institut d'étude des religions et de la laïcité. Après une première publication portant sur le thème de la sacralisation du pouvoir dans la série «Problème d'histoire des religions» en 2003, l'ambition de ce groupe de chercheurs était de réhabiliter la violence de guerre comme objet d'histoire, y compris d'histoire religieuse. Comme le précise Jean-Philippe Schreiber dans son avant-propos, c'est à partir d'une réflexion sur l'articulation entre la dimension anthropologique de la bataille comme expression du sacré et la dimension théologique de la sacralisation de la guerre que ce séminaire s'est porté vers l'analyse, d'une part, de la ritualisation du conflit, d'autre part, de sa sacralisation et de sa limitation par la codification du droit de la guerre (jus ad bellum et jus in bello). Ces études des relations entre guerre et religions ont une double originalité : elles se situent à la croisée d'une lecture anthropologique et d'une optique théologique ; elles explorent le cadre classique d'émergence et de constitution des doctrines de la guerre juste - le christianisme dans l'espace de l'Europe occidentale du XVI ${ }^{\mathrm{e}}$ au XX $\mathrm{XX}^{\mathrm{e}}$ siècle - sans s'y restreindre, puisqu'une série d'analyses procède par variations géo-temporelles en s'ouvrant au monde païen (la Rome antique), aux deux autres monothéismes (l'histoire juive et l'islam médiéval) et à l'Extrême-Orient (la Chine du IV siècle avant notre ère).

La première série d'études porte sur l'espace historique du christianisme. S'inscrivant dans le contextualisme de Quentin Skinner, qui prend ses distances avec une lecture internaliste des textes politiques pour les replacer dans leur contexte idéologique, Monique Weis articule les transformations des théories de la guerre juste aux $\mathrm{XVI}^{\mathrm{e}}$ et $\mathrm{XVII}^{\mathrm{e}}$ siècles aux usages des arguments religieux dans les tentatives de justification de la 
guerre. La guerre juste se distingue désormais de la guerre sainte ou de la croisade (l'idéal de la croisade restant néanmoins présent dans le cadre des affrontements avec l'Empire Ottoman), au point où les arguments religieux sont parfois relativisés, voire dénoncés comme visant simplement à légitimer les motivations réelles des guerres de religion. Ces guerres - que l'auteur conçoit avec Georges Livet comme des guerres idéologiques d'un genre nouveau - apparaissent ainsi paradoxalement comme marquant un moment décisif dans la sécularisation du politique, dans l'autonomisation de la raison politique par rapport aux intérêts confessionnels. Cette transformation est rendue possible théoriquement par le nouveau cadre juridique dressé par Grotius, qui sépare le droit naturel du droit divin positif, universalise le droit des gens et définit une religion naturelle dont l'universalisme peut tout à la fois unir les hommes sous des normes communes et séculariser les guerres qui les opposent. Le juriste néerlandais prend de la sorte ses distances avec des réformateurs tels que Luther, Zwingli et Calvin, qui maintiennent la guerre dans un cadre religieux. La sécularisation de la guerre accompagnerait ainsi une séparation plus générale du politique et du religieux.

Le rôle de la théologie et de la casuistique catholiques, du dogme et de son application aux cas particuliers, au sein même des batailles, sont analysés par Olivier Chaline dans le texte qu'il consacre à la bataille de la Montagne Blanche contre les protestants en 1620, la situant par rapport à deux autres batailles menées contre les Turcs, en 1571 (Lépante) et en 1683. Toutes ont en commun de mettre en jeu les traits spécifiques de la foi catholique face à l'infidèle ou à l'hérétique (assimilé au Turc) à travers le rôle joué par des hommes d'Église sur les lieux mêmes des combats. S'inscrivant dans une lutte opposant les états de Bohême à leur roi Ferdinand de Habsbourg, la bataille de la Montagne Blanche est rapportée au cadre des guerres justes qui fournit une justification théorique à l'usage des armes et s'appuie sur la casuistique développée par le P. Becan et le P. Dominique de Marie-Jésus. Le combat peut ainsi apparaître comme le jugement de Dieu, et la bataille comme le rétablissement providentiel de l'ordre violé. Olivier Chaline montre ainsi la manière dont la lutte menée par les soldats a été véritablement galvanisée par des hommes d'Église dont la présence parfois mystique (pour le P. Dominique qui, subvertissant la hiérarchie militaire et la prudence tactique, promet en véritable inspiré la victoire si la bataille est engagée) a réveillé l'imaginaire de la croisade et la fureur des soldats, notamment à travers la défense faite de la piété mariale, des saints et des images religieuses contre les ennemis iconoclastes.

Un saut de l'âge classique à l'histoire contemporaine sépare ces études des suivantes, marquant la volonté d'une approche comparatiste. Si l'imaginaire religieux hante les engagements guerriers, Ernest Psichari - l'un des premiers catholiques célèbres à mourir sur le front (en 1914) avant Charles Péguy, Fournier, Pierre Dupouey ou Joseph Lotte - fournit l'exemple même d'une alliance entre la défense de la France lors de la Grande Guerre 
et celle du catholicisme. Issu d'un milieu socialiste athée, converti au catholicisme en 1913, Psichari a développé une mystique de l'engagement militaire, identifiant sacrifice guerrier et sacrifice religieux, soldat et chrétien, mort pour la patrie et mort pour l'Église, mystique nationale et mystique religieuse, appartenance nationale et foi catholique. Frédérique Dufour retrace ainsi la manière dont est interprétée la mort de Psichari et reconstruite sa mémoire (opposant son ami Jacques Maritain à Maurice Barrès), d'une part, à des fins de propagande - tout particulièrement en ce qui concerne les convertis - d'autre part, à des fins prosélytes. Si pour les catholiques contemporains du conflit, la guerre est à la fois châtiment, expiation et bienfait, les morts pour la patrie apparaissent comme autant de Christ sacrifiés contre un ennemi Réformé. Frédérique Dufour analyse cette conception déjà présente dans les écrits de Psichari, pour qui l'armée constitue un instrument aux ordres de Dieu dont la mission est de racheter la France, de faire barrage à la barbarie religieuse germanique, mêlant combat terrestre et combat spirituel.

Cette mystique du combat apparaît pourtant, comme le souligne Annette Becker, dans un contexte national où prédomine la volonté de mettre fin à la guerre, inscrivant la paix dans une réalisation de la promesse messianique. Deux types de discours religieux se lient à la guerre et continuent de s'opposer jusque dans les années vingt et trente : l'idéal patriotique qui exalte la haine de l'ennemi à qui sont imputées les atrocités des combats, puis, après la guerre, le messianisme pacifiste. Après l'armistice et dans les années qui ont suivi, le «processus de démobilisation culturelle » n'empêche pas une sorte de continuation de la guerre à travers les représentations qu'en forment les anciens ennemis. On assiste alors, souligne Annette Becker, à une réfraction de la violence de la guerre dans l'espace du politique de l'après-guerre, qui rencontrera le messianisme nazi. L'auteur montre ainsi, d'une part, les liens entre la violence de 1914-1918, la violence politique des années 1920 et 1930, et la violence du conflit de 1939-1945, d'autre part, le paradoxe de cette Grande Guerre qui est acceptée dans les années 1914-1918 pour être ensuite refusée, dans une inversion de la culture de guerre qui passe, chez nombre d'intellectuels ou d'artistes, par une nouvelle élaboration de la mémoire de la guerre et un pacifisme militant.

L'union du catholicisme, du nationalisme et du bellicisme n'a pas empêché l'émergence de certaines figures alliant le catholicisme au pacifisme. Anne Morelli expose ainsi la position singulière de Don Sturzo, fondateur du Parti populaire italien, prêtre anti-belliciste en rupture avec les positions dominantes du Vatican et contraint à l'exil jusqu'en 1946. Don Sturzo demeure pacifiste au nom de la morale chrétienne, position qu'il développe dans des articles mais aussi dans un ouvrage sur la communauté internationale et le droit de la guerre. L'argument central consiste à opposer le caractère irrationnel de la guerre à la nature rationnelle de l'homme qui, en développant sa rationalité par l'éducation à la paix, mettra fin à la 
guerre. Le christianisme entre alors au service d'une critique des doctrines de la guerre juste, dénoncées comme illégitimes et immorales, comme autant de discours justifiant la raison d'État.

Le collectif se poursuit par une série d'articles qui explorent d'autres champs que ceux du christianisme européen moderne et contemporain. Une première ouverture vers le monde romain (Baudouin Decharneux), qui analyse le droit fécial et la pratique de la devotio décrites dans deux récits de batailles (Veseris et Sentinum), met en lumière la cohérence religieuse du monde romain, dans le sillage des analyses de Georges Dumézil, et la dimension du code symbolique qui investit les pratiques guerrières. Une autre ouverture a lieu vers l'islam médiéval, qui a codifié la guerre d'autant plus tôt que la lutte fut un élément de mission du Prophète. Comme le montre Jean-Charles Ducène, si la doctrine classique de la guerre sainte est élaborée au $\mathrm{IX}^{\mathrm{e}}$ siècle et réactualisée aux $\mathrm{XII}^{\mathrm{e}}$ et $\mathrm{XIII}^{\mathrm{e}}$ siècles, elle devient au XIX $\mathrm{X}^{\mathrm{e}}$ siècle - du fait de l'occidentalisation des mentalités et du droit - un discours politique, en même temps qu'elle ne se conçoit plus qu'envers les infidèles. Très présente également dans le texte biblique hébraïque, la question de la guerre traverse l'histoire juive, au point de constituer, pour Régine Azria, une sorte de fil rouge reliant l'Antiquité au présent, les textes fondateurs, leurs commentaires théologiques et philosophiques, au sionisme et à l'histoire nationale israélite. Si les textes fondateurs comprennent tout à la fois une typologie des guerres et un usage éthique de la violence, les trois périodes définissant un rapport spécifique à la guerre (biblique, exilique et post-exilique) apportent des références sur lesquelles se fondent des positions aussi différentes que le bellicisme hérö̈que, le mysticisme messianique ou apocalyptique. Jean Lévi oriente pour finir cette étude des théologies de la guerre vers l'Extrême-Orient, développant une analyse du Sunzi - texte paradigmatique de la pensée chinoise de l'art de la guerre écrit vers la fin du IV siècle avant notre ère, à une période de transformation en profondeur de la Chine.

Ce collectif offre ainsi une approche véritablement plurielle des théologies de la guerre, tant par ses ouvertures géo-temporelles justifiées par une approche historique comparatiste, que par les champs disciplinaires qu'il mobilise, liant la théologie au droit, à l'histoire et à la théorie politique.

Julie SAADA, IUFM de Paris, Université Paris 9.

Jean-Pierre Moisset, Histoire du catholicisme, Paris, Flammarion, 2006, $24 \mathrm{~cm}, 529$ p., $24 €$.

Dans la collection de synthèse historique où paraît cet ouvrage, il se distingue par l'étendue exceptionnelle du sujet traité. Et l'on peut considérer que l'auteur a gagné son pari en fournissant en cinq cents pages une vision 